\title{
The Effect of Korean Red Ginseng on Sexual Function in Premenopausal Women: Placebo-Controlled, Double-Blind, Crossover Clinical Trial
}

\author{
Ho Seok Chung, Insang Hwang, Kyung Jin Oh, Mi Na Lee, and Kwangsung Park \\ Department of Urology, Chonnam National University, 671 Jebongno, Donggu, Gwangju 61469, Republic of Korea
}

Correspondence should be addressed to Kwangsung Park; uropark@gmail.com

Received 17 August 2015; Accepted 19 November 2015

Academic Editor: David Mischoulon

Copyright (C) 2015 Ho Seok Chung et al. This is an open access article distributed under the Creative Commons Attribution License, which permits unrestricted use, distribution, and reproduction in any medium, provided the original work is properly cited.

\begin{abstract}
This study investigated whether Korean red ginseng (KRG) extracts could improve sexual function in premenopausal women. Forty-one premenopausal women participated in this placebo-controlled, double-blind, and crossover clinical study with administration of either three ginseng capsules (1 g per capsule) or placebo daily. After 8 weeks of medication of KRG or placebo, medication was changed for the subjects to placebo or KRG after 2 weeks of washout period. The efficacy of KRG extracts was measured by using Female Sexual Function Index (FSFI). Results. Twenty-three women completed the study. Total FSFI scores increased after KRG treatment (from $20.13 \pm 2.87$ to $23.98 \pm 4.10, p=0.015$ ) and placebo treatment (from $20.06 \pm 2.64$ to $23.78 \pm 3.28, p=0.003)$. However, this change was not significantly different between the two groups $(p=0.702)$. KRG treatment significantly improved sexual desire, arousal, orgasm, and satisfaction domains; however, there was no treatment effect compared with placebo. There was a case of gastric discomfort after taking KRG extracts. Oral administration of KRG extracts improved sexual function in premenopausal women; however, there were no statistical significant changes compared to placebo. It implies that KRG extracts have a substantial placebo effect in premenopausal women with sexual dysfunction.
\end{abstract}

\section{Introduction}

Female sexual dysfunction (FSD) is prevalent problem which affects approximately $40 \%$ of women [1]. FSD is a multifactorial phenomenon which is composed of medical and psychosocial aspects $[2,3]$. While male sexual dysfunctions are often treated with pharmacological agents, FSD still needs further research and clinical trials to find efficacious therapeutic options [4-9].

Korean red ginseng (KRG) (Panax ginseng Meyer) is an herb of the family Araliaceae, which is a slow growing perennial plant with fleshy roots [10]. It grows in cooler climate regions of the Northern Hemisphere and is used as a traditional complementary and alternative medicine [11]. It contains triterpenes ginseng saponins called ginsenosides, which are responsible for its various pharmacological effectiveness, such as anti-inflammatory activity, effects on pulmonary function, and improvement of cognition in Alzheimer's disease and sexual function [12-17].
In our previous study of menopausal women, we reported that KRG improved sexual arousal [12]. In animal studies, we found that KRG has a relaxing effect on clitoral corpus cavernosal smooth muscle and vaginal smooth muscle in rabbit model [18]. Also, we found that KRG may have estrogenic effects on female rats [19]. From these results, we hypothesized that KRG may improve sexual function of premenopausal women with FSD. The aim of this study was to determine the effects of KRG on sexual function in premenopausal women.

\section{Materials and Methods}

The study protocol was reviewed and approved by an institutional review board (CRE 11156-7) of Chonnam National University Hospital.

2.1. Subjects. The subjects of study were premenopausal women with female sexual dysfunction in a communitybased population from September 2011 to May 2012. We 
enrolled premenopausal women who had all of the following inclusion criteria: (1) Female Sexual Function Index (FSFI) questionnaire score less than 26.5 at the initial evaluation; (2) participants being required to have sexual intercourse interaction at least 4 times a month with a steady sexual partner; (3) women aged between 31 and 51 years with regular menstruation at least for 1 year; and (4) women who decided to participate in this study with their own will. All of the participants were provided information related to this study with written informed consent. They were also informed that they could quit the participation at any time during the study.

Exclusion criteria were as follows: (1) coronary artery disease or other heart problems such as significant arrhythmia; (2) uncontrolled diabetes mellitus; (3) uncontrolled hypertension; (4) blood pressure lower than 90/50 mmHg; (5) a history of radical hysterectomy; (6) anatomical deformity of external genitalia; (7) a history of cerebrovascular disease or central nervous system disease; (8) a history of spinal cord injury or related surgery; (9) abnormal level of serum liver enzymes; (10) serum creatinine $>2.5 \mathrm{mg} / \mathrm{dL}$; (11) intake of medicine such as amlodipine, valerian, and lorazepam (which are known to have interactions with ginseng); (12) a history of hormonal treatment for sexual dysfunction during the past two weeks; (13) a history of chemotherapy or pelvic radiation treatment; (14) sexual dysfunction which was caused by psychogenic problem; and (15) sexual dysfunction which was caused by low level of testosterone (less than $0.66 \mathrm{pg} / \mathrm{mL}$ ).

2.2. Study Design. The study was a randomized, doubleblind, and placebo-controlled crossover study. In each participant, total protocol period was 20 weeks. The first two weeks was for collecting baseline data. During the following 8 weeks, double-blind, placebo-controlled crossover study was done with randomly allocated treatment arms. Two weeks of washout period was scheduled in between them.

At initial visit (visit 1), screening was done. Medical interview, FSFI, physical examination and baseline vital sign were checked. The laboratory study including serum hormonal level (total testosterone, free testosterone, and estradiol) and urine pregnancy test was conducted. After first visit, any participants who met exclusion criteria were excluded. For all of enrolled patients, written informed consents were obtained.

At second visit (visit 2), baseline data was collected and treatment arms were started. The subjects were divided into two groups, randomly. This study was double blinded that all subjects, investigators, pharmacists, and study staff did not know to which group the subjects were enrolled. One group was asked to take six capsules of KRG daily for 8 weeks. The other group was asked to take placebo capsules with the same periods. After 8 weeks of taking medication, 2 weeks of washout period without any medication was followed. After washout period, groups were switched to the other group medication (crossover) for 8 weeks again. Detailed information for KRG and placebo capsule will be described later.

Before the beginning of each treatment (visits 2 and 5), baseline data including sexual function and hormonal levels were measured. Detailed information for sexual function measurement will be described later. Every 4 weeks during medication, the subjects were required to visit the clinic for assessment of their condition and any adverse event (visits $3,4,6$, and 7). Sexual function and hormonal level measurement were done repeatedly at each end of the treatment arm (visits 1, 4, and 7). Due to the fact that the study was done as crossover design, all patients served as their own controls. A well-trained female staff conducts the interview with subjects. Interview for sexual function measurement and adverse events was conducted by the same female interviewer.

2.3. KRG and Placebo Capsules. KRG capsules and placebo capsules were provided by the Korean Ginseng Corporation (Daejeon, Korea). A KRG capsule contains $500 \mathrm{mg}$ of dried ginseng powder from the root of six-year-old Panax ginseng C.A. Meyer. The capsule was made of hydroxypropyl methylcellulose, pectin, purified water, sucrose fatty acid ester, glycerin, calcium gluconate, and glacial acetic acid. KRG contained the following active compounds: -Rb1, $5.61 \mathrm{mg} / \mathrm{g}$; -Rb2, $2.03 \mathrm{mg} / \mathrm{g}$; -Rc, $2.20 \mathrm{mg} / \mathrm{g}$; -Rd, $0.39 \mathrm{mg} / \mathrm{g}$; -Re, $1.88 \mathrm{mg} / \mathrm{g}$; -Rf, $0.89 \mathrm{mg} / \mathrm{g}$; -Rg1, $3.06 \mathrm{mg} / \mathrm{g}$; -Rg2(s), $0.15 \mathrm{mg} / \mathrm{g}$; -Rg3(r), $0.08 \mathrm{mg} / \mathrm{g} ;-\mathrm{Rg} 3(\mathrm{~s}), 0.17 \mathrm{mg} / \mathrm{g}$; -Rh1, $0.30 \mathrm{mg} / \mathrm{g}$; and other minor ginsenosides. A placebo capsule contains starch to mimic KRG capsule. The flavor and the appearance of two capsules were identical.

2.4. Assessment of Female Sexual Function. For evaluation of the female sexual function, FSFI was used [20]. We used the Korean version of FSFI [21]. This questionnaire consists of 19 items in 6 domains: desire (two items), arousal (four items), vaginal lubrication (four items), orgasm (three items), global satisfaction (three items), and pain (three items). The items for sexual desire and satisfaction were measured using a 5point scale while the rest of the questions were measured with a 6-point scale. The lowest point was 4 and the highest point was 95; thus, lower scores reflected more severe disorder in terms of sexual function.

The FSFI was measured at the beginning and at the end of each medication (visits 2, 4, 5, and 7). For the assessment of secondary efficacy, we evaluated the total and each score of the 6 domains of the FSFI.

2.5. Analysis. At the end of the 8 weeks of each treatment arm, we compared all the variables between the ginseng group and placebo group. Chi-square test, $t$-test (crossover analysis), and $Z$-test were performed. Repeated-measures analysis was used to test the carryover effect and period effect. For statistical significance, $p$ value less than 0.05 was used. Statistical analysis was done by the Statistical Package for Social Science PC+, version 19.0 (SPSS Inc., Chicago, IL, USA).

\section{Results}

3.1. Study Population. Of a total of 41 subjects, 9 subjects were excluded, and 32 subjects were randomly divided into KRG group and placebo group. One subject wanted to quit due to side effect (gastric discomfort), and 8 subjects dropped out during the study because of a lack of subjective improvement. Finally, 23 subjects completed the study (Table 1). Twelve subjects started KRG medication first and placebo medication 
TABLE 1: Baseline characteristics of patients.

\begin{tabular}{lccc}
\hline & $\begin{array}{c}\text { KRG-placebo } \\
(n=12)\end{array}$ & $\begin{array}{c}\text { Placebo-KRG } \\
(n=11)\end{array}$ & $p$ value \\
\hline Age (yr) & $38.25 \pm 5.92$ & $37.36 \pm 6.28$ & 0.449 \\
Marriage duration (yr) & $12.92 \pm 8.26$ & $12.09 \pm 7.30$ & 0.651 \\
$\begin{array}{l}\text { Duration of FSD } \\
\text { Chronic medical disease, } n\end{array}$ & $2.88 \pm 1.69$ & $2.05 \pm 1.17$ & 0.608 \\
$\quad$ Hypothyroidism & 0 & 1 & \\
$\begin{array}{l}\text { Delivery history, } n \\
\quad \text { Vaginal }\end{array}$ & & & \\
$\quad$ Cesarean section & 3 & 8 & \\
FSFI & $21.53 \pm 3.19$ & $20.12 \pm 3.58$ & 0.316 \\
\hline
\end{tabular}

Data are presented as mean \pm standard deviation unless otherwise indicated. KRG: Korean red ginseng; FSD: female sexual dysfunction; FSFI: Female Sexual Dysfunction Index.

later (KRG-placebo group). Eleven subjects started placebo medication first and KRG medication later (placebo-KRG group). All of them were without other medical history except only one participant who had combined hypothyroidism.

3.2. Sexual Function: FSFI. Total FSFI scores increased after KRG treatment (from $20.13 \pm 2.87$ to $23.98 \pm 4.10, p=0.015$ ) and placebo treatment (from $20.06 \pm 2.64$ to $23.78 \pm 3.28, p=$ $0.003)$. However, this change was not significantly different compared to that of placebo group $(p=0.702)$. No period effect or carryover effect was observed. The sexual desire was significantly improved after 8-week treatment of KRG while there was no significant effect in placebo. However, there was no significant treatment effect between two groups. Overall, KRG treatment significantly improved sexual desire, arousal, orgasm, and satisfaction domains; however, there was no treatment effect compared with placebo (Table 2).

3.3. Hormone Levels and Side Effects. Changes in sexual hormones during the study were described in Table 3. Mean total testosterone level increased from $0.24 \pm 0.89 \mathrm{ng} / \mathrm{mL}$ to $0.29 \pm 0.12 \mathrm{ng} / \mathrm{mL}$ and estradiol increased from $153.99 \pm$ $88.93 \mathrm{pg} / \mathrm{mL}$ to $175.60 \pm 149.77 \mathrm{pg} / \mathrm{mL}$ in the KRG group. However, similar findings were also observed in the placebo group. There were no statistically significant changes between KRG treatment and placebo group (testosterone, $p=0.618$; estradiol, $p=0.450$ ).

Only one adverse event was reported in this study. It was a mild gastric discomfort after intake of KRG.

\section{Discussion}

Female sexual dysfunction may worsen the whole life of affected women $[22,23]$. Women with sexual dysfunction showed lower quality of life and less satisfaction with their partner [22]. Female sexual dysfunction was associated with psychological and emotional distress as well as significantly lower sexual satisfaction, lower self-esteem, and more anxiety $[24,25]$.
Among the complementary and alternative medicines with improving sexual function, ginseng appears to be one of the attractive options. Ginseng has several pharmacological activities $[26,27]$. In an animal model study, we found that KRG relaxed the clitoral corpus cavernosal smooth muscle and vaginal smooth muscle in rabbits by the NO-cGMP pathway. Also, KRG hyperpolarized the $\mathrm{Ca}^{2}$-activated $\mathrm{K}^{+}$channels [18]. Ginseng enhances the NO synthesis in the endothelium and acts as an antioxidant with a protective effect [13, 28]. These effects of ginseng have potential improvement of female sexual function. In menopausal women, we reported that improvement of female sexual function (particularly arousal) was shown after 8 weeks' intake of KRG [12]. According to previous study, we hypothesized that KRG may improve sexual function in premenopausal women.

In KRG treatment group of this study, FSFI scores were significantly increased after medication. However, improvement of FSFI scores in the KRG group was not statistically different compared to placebo group. There were possible explanations as follows. First, there was a large placebo response which makes a difficulty in demonstrating a difference between active treatment and placebo groups. Bradford reported that $40 \%$ or more of women improved significantly after a placebo intervention for hypoactive sexual desire disorder and female sexual arousal disorder [8]. Second, there may be an influence of menstrual cycle of the subjects. We did not consider the menstrual cycle of the subject when we checked a questionnaire. Roney and Simmons reported that hormone level was associated with sexual behavior [29]. According to their study, women's subjective sexual desire exhibited in periovulatory peaks and estrogen had a positive effect on sexual desire. For a more accurate assessment, interviewing the subjects of study at similar point of menstrual cycle is needed.

We previously reported the KRG improved sexual function in menopausal women [12]. After 8 weeks of treatment of KRG, there was an improvement of sexual function in sexual arousal domain. It may be associated with a phytoestrogen effect of ginseng [19]. There was a report that red ginseng could relieve menopausal symptoms [30].

Importantly, KRG did not show significant side effect compared to placebo in our study. There was one adverse event of a mild gastric discomfort after KRG treatment. KRG was a traditional herbal medicine that has been used for maintenance and improvement of human health in Asian countries for a long time. In the laboratory test, there were no significant findings compared to placebo.

The present study had some limitations. First, we did not check the partners' sexual function. Female sexual function may be influenced by partner's sexual status. Second, there was no study to prove an optimal dose of KRG for improving sexual function. Third, we did not consider a menstrual cycle of participants in this study. Menstrual cycle may influence a hormone level in women.

\section{Conclusion}

Oral administration of KRG extracts improved sexual function in premenopausal women; however, there were no 
TABLE 2: The results of Female Sexual Function Index in the Korean red ginseng and placebo groups.

\begin{tabular}{|c|c|c|c|c|c|c|c|c|c|}
\hline & \multicolumn{3}{|c|}{$\mathrm{KRG}(n=23)$} & \multicolumn{3}{|c|}{ Placebo $(n=23)$} & \multirow{2}{*}{$\begin{array}{c}\text { Period effect } \\
(p)\end{array}$} & \multirow{2}{*}{$\begin{array}{l}\text { Carryover effect } \\
(p)\end{array}$} & \multirow{2}{*}{$\begin{array}{c}\text { Treatment effect } \\
(p)^{\ddagger}\end{array}$} \\
\hline & Baseline & $8 \mathrm{wk}$ & $p^{\dagger}$ & Baseline & $8 \mathrm{wk}$ & $p^{\dagger}$ & & & \\
\hline Desire & $2.70 \pm 0.65$ & $3.70 \pm 0.80$ & 0.003 & $2.50 \pm 0.64$ & $3.05 \pm 0.73$ & 0.058 & 0.514 & 0.947 & 0.228 \\
\hline Arousal & $3.00 \pm 0.72$ & $3.72 \pm 0.90$ & 0.040 & $2.92 \pm 0.55$ & $3.55 \pm 0.81$ & 0.017 & 0.693 & 0.883 & 0.431 \\
\hline Lubrication & $3.97 \pm 0.78$ & $4.23 \pm 0.84$ & 0.562 & $3.76 \pm 0.81$ & $4.31 \pm 0.80$ & 0.054 & 0.022 & 0.306 & 0.770 \\
\hline Orgasm & $3.20 \pm 0.64$ & $3.90 \pm 1.01$ & 0.028 & $3.42 \pm 0.60$ & $4.18 \pm 0.62$ & 0.007 & 0.288 & 0.789 & 0.288 \\
\hline Satisfaction & $3.40 \pm 0.50$ & $4.00 \pm 0.85$ & 0.027 & $3.49 \pm 0.60$ & $3.89 \pm 0.69$ & 0.040 & 0.354 & 0.579 & 0.894 \\
\hline Pain & $3.87 \pm 1.17$ & $4.43 \pm 1.34$ & 0.212 & $3.96 \pm 1.30$ & $4.80 \pm 0.74$ & 0.012 & 0.764 & 0.411 & 0.096 \\
\hline Total & $20.13 \pm 2.87$ & $23.98 \pm 4.10$ & 0.015 & $20.06 \pm 2.64$ & $23.78 \pm 3.28$ & 0.003 & 0.266 & 0.535 & 0.702 \\
\hline
\end{tabular}

KRG: Korean red ginseng.

${ }^{\dagger}$ Wilcoxon signed rank test using baseline and treatment of 8 weeks.

${ }^{\ddagger}$ Wilcoxon signed rank test using KRG and placebo.

TABLE 3: Changes of hormone level after each medication.

\begin{tabular}{|c|c|c|c|c|c|c|}
\hline & & $\begin{array}{l}\text { KRG group } \\
(n=23)\end{array}$ & $\begin{array}{l}\text { Placebo group } \\
\quad(n=23)\end{array}$ & Period effect $(p)$ & Carryover effect $(p)$ & Treatment effect $(p)$ \\
\hline \multirow{2}{*}{$\begin{array}{l}\text { Total testosterone } \\
(\mathrm{ng} / \mathrm{mL})\end{array}$} & Baseline & $0.24 \pm 0.19$ & $0.24 \pm 0.14$ & \multirow{2}{*}{0.310} & \multirow{2}{*}{0.510} & \multirow{2}{*}{0.618} \\
\hline & $8 \mathrm{wk}$ & $0.29 \pm 0.12$ & $0.29 \pm 0.18$ & & & \\
\hline \multirow{2}{*}{$\begin{array}{l}\text { Free testosterone } \\
(\mathrm{ng} / \mathrm{mL})\end{array}$} & Baseline & $0.49 \pm 0.23$ & $0.49 \pm 0.25$ & \multirow{2}{*}{0.426} & \multirow{2}{*}{0.483} & \multirow{2}{*}{0.628} \\
\hline & $8 \mathrm{wk}$ & $0.49 \pm 0.24$ & $0.52 \pm 0.31$ & & & \\
\hline \multirow{2}{*}{ Estradiol $(\mathrm{pg} / \mathrm{mL})$} & Baseline & $153.99 \pm 88.93$ & $124.46 \pm 87.99$ & \multirow{2}{*}{0.231} & \multirow{2}{*}{0.612} & \multirow{2}{*}{0.450} \\
\hline & $8 \mathrm{wk}$ & $175.60 \pm 149.77$ & $150.13 \pm 140.30$ & & & \\
\hline
\end{tabular}

statistical significant changes compared to placebo. It implies that KRG extracts have a substantial placebo effect in premenopausal women with sexual dysfunction. Further studies are needed to evaluate the effect of KRG extracts on specific disorders of female sexual dysfunction, such as female sexual desire disorder or arousal disorder.

\section{Conflict of Interests}

No potential conflict of interests relevant to this paper was reported.

\section{Acknowledgments}

This work was supported by the 2011 grant from the Korean Society of Ginseng funded by Korea Ginseng Corporation and by a grant (CRI13904-21.3) from the Chonnam National University Hospital Biomedical Research Institute.

\section{References}

[1] E. O. Laumann, A. Paik, and R. C. Rosen, "Sexual dysfunction in the United States: prevalence and predictors," The Journal of the American Medical Association, vol. 281, no. 6, pp. 537-544, 1999.

[2] A. Goshtasebi, M. Vahdaninia, and A. R. Foroshani, "Prevalence and potential risk factors of female sexual difficulties: an urban Iranian population-based study," Journal of Sexual Medicine, vol. 6, no. 11, pp. 2988-2996, 2009.

[3] R. Basson, J. Berman, A. Burnett et al., "Report of the international consensus development conference on female sexual dysfunction: definitions and classifications," The Journal of Urology, vol. 163, no. 3, pp. 888-893, 2000.

[4] L. Incrocci and P. T. Jensen, "Pelvic radiotherapy and sexual function in men and women," Journal of Sexual Medicine, vol. 10, supplement 1, pp. 53-64, 2013.

[5] C. M. Dording, R. A. LaRocca, K. A. Hails et al., "The effect of sildenafil on quality of life," Annals of Clinical Psychiatry, vol. 25, no. 1, pp. 3-10, 2013.

[6] M. J. Bly, J. R. Bishop, K. L. H. Thomas, and V. L. Ellingrod, "Pglycoprotein (PGP) polymorphisms and sexual dysfunction in female patients with depression and SSRI-associated sexual side effects," Journal of Sex and Marital Therapy, vol. 39, no. 3, pp. 280-288, 2013.

[7] L. Kashani, F. Raisi, S. Saroukhani et al., "Saffron for treatment of fluoxetine-induced sexual dysfunction in women: randomized double-blind placebo-controlled study," Human Psychopharmacology, vol. 28, no. 1, pp. 54-60, 2013.

[8] A. Bradford, "Listening to placebo in clinical trials for female sexual dysfunction," Journal of Sexual Medicine, vol. 10, no. 2, pp. 451-459, 2013.

[9] K. Wylie and F. Malik, "Review of drug treatment for female sexual dysfunction," International Journal of STD and AIDS, vol. 20, no. 10, pp. 671-674, 2009.

[10] S. W. Chan, "Panax ginseng, Rhodiola rosea and Schisandra chinensis," International Journal of Food Sciences and Nutrition, vol. 63, supplement 1, pp. 75-81, 2012.

[11] J. H. Jung, I. G. Kang, D. Y. Kim, Y. J. Hwang, and S. T. Kim, "The effect of Korean red ginseng on allergic inflammation in a murine model of allergic rhinitis," Journal of Ginseng Research, vol. 37, no. 2, pp. 167-175, 2013. 
[12] K.-J. Oh, M.-J. Chae, H.-S. Lee, H.-D. Hong, and K. Park, "Effects of korean red ginseng on sexual arousal in menopausal women: placebo-controlled, double-blind crossover clinical study," Journal of Sexual Medicine, vol. 7, no. 4, part 1, pp. 14691477, 2010.

[13] Y. D. Choi, C. W. Park, J. Jang et al., "Effects of Korean ginseng berry extract on sexual function in men with erectile dysfunction: a multicenter, placebo-controlled, double-blind clinical study," International Journal of Impotence Research, vol. 25, no. 2, pp. 45-50, 2013.

[14] S.-Y. Han, H.-X. Li, X. Ma et al., "Evaluation of the antimyocardial ischemia effect of individual and combined extracts of Panax notoginseng and Carthamus tinctorius in rats," Journal of Ethnopharmacology, vol. 145, no. 3, pp. 722-727, 2013.

[15] H. Lee, D. Park, and M. Yoon, "Korean red ginseng (Panax ginseng) prevents obesity by inhibiting angiogenesis in high fat diet-induced obese C57BL/6J mice," Food and Chemical Toxicology, vol. 53, pp. 402-408, 2013.

[16] Z. Liu, W. Li, X. Li et al., "Antidiabetic effects of malonyl ginsenosides from Panax ginseng on type 2 diabetic rats induced by high-fat diet and streptozotocin," Journal of Ethnopharmacology, vol. 145, no. 1, pp. 233-240, 2013.

[17] Y.-H. Kim, G.-H. Kim, J.-H. Shin, K.-S. Kim, and J.-S. Lim, "Effect of Korean red ginseng on testicular tissue injury after torsion and detorsion," Korean Journal of Urology, vol. 51, no. 11, pp. 794-799, 2010.

[18] S.-O. Kim, M. K. Kim, H.-S. Lee, J. K. Park, and K. Park, "The effect of Korean red ginseng extract on the relaxation response in isolated rabbit vaginal tissue and its mechanism," Journal of Sexual Medicine, vol. 5, no. 9, pp. 2079-2084, 2008.

[19] S. O. Kim, M. Lee, Y. Xui et al., "Effects of Korean red ginseng on the vaginal blood flow and sturcture in female casttrated rats," Korean Journal of Urology, vol. 47, no. 8, pp. 888-894, 2006.

[20] R. Rosen, C. Brown, J. Heiman et al., "The Female Sexual Function Index (FSFI): a multidimensional self-report instrument for the assessment of female sexual function," Journal of Sex and Marital Therapy, vol. 26, no. 2, pp. 191-208, 2000.

[21] H. Y. Kim, H. S. So, K. S. Park, S. J. Jeong, J. Y. Lee, and S. B. Ryu, "Development of the Korean-version of female sexual function index (FSFI)," Korean Journal of Andrology, vol. 20, no. 1, pp. 50-56, 2002.

[22] C. Günzler and M. M. Berner, "Efficacy of psychosocial interventions in men and women with sexual dysfunctions-a systematic review of controlled clinical trials. Part 2. The efficacy of psychosocial interventions for female sexual dysfunction," Journal of Sexual Medicine, vol. 9, no. 12, pp. 3108-3125, 2012.

[23] B. S. Christensen, M. Grønbæk, M. Osler, B. V. Pedersen, C. Graugaard, and M. Frisch, "Associations between physical and mental health problems and sexual dysfunctions in sexually active danes," Journal of Sexual Medicine, vol. 8, no. 7, pp. 18901902, 2011.

[24] S. R. Leiblum, P. E. Koochaki, C. A. Rodenberg, I. P. Barton, and R. C. Rosen, "Hypoactive sexual desire disorder in postmenopausal women: US results from the Women's International Study of Health and Sexuality (WISHeS)," Menopause, vol. 13, no. 1, pp. 46-56, 2006.

[25] U. Hartmann, K. Heiser, C. Rüffer-Hesse, and G. Kloth, "Female sexual desire disorders: subtypes, classification, personality factors and new directions for treatment," World Journal of Urology, vol. 20, no. 2, pp. 79-88, 2002.

[26] B. Hong, Y. H. Ji, J. H. Hong, K. I. Y. Nam, and T. Y. Ahn, “A double-blind crossover study evaluating the efficacy of korean red ginseng in patients with erectile dysfunction: a preliminary report," The Journal of Urology, vol. 168, no. 5, pp. 2070-2073, 2002.

[27] D.-J. Jang, M. S. Lee, B.-C. Shin, Y.-C. Lee, and E. Ernst, "Red ginseng for treating erectile dysfunction: a systematic review," British Journal of Clinical Pharmacology, vol. 66, no. 4, pp. 444450, 2008.

[28] E. Tachikawa, K. Kudo, K. Harada et al., "Effects of ginseng saponins on responses induced by various receptor stimuli," European Journal of Pharmacology, vol. 369, no. 1, pp. 23-32, 1999.

[29] J. R. Roney and Z. L. Simmons, "Hormonal predictors of sexual motivation in natural menstrual cycles," Hormones and Behavior, vol. 63, no. 4, pp. 636-645, 2013.

[30] S. Y. Kim, S. K. Seo, Y. M. Choi et al., "Effects of red ginseng supplementation on menopausal symptoms and cardiovascular risk factors in postmenopausal women: a double-blind randomized controlled trial," Menopause, vol. 19, no. 4, pp. 461-466, 2012. 


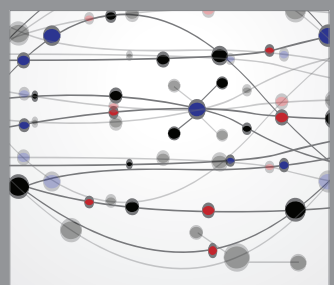

The Scientific World Journal
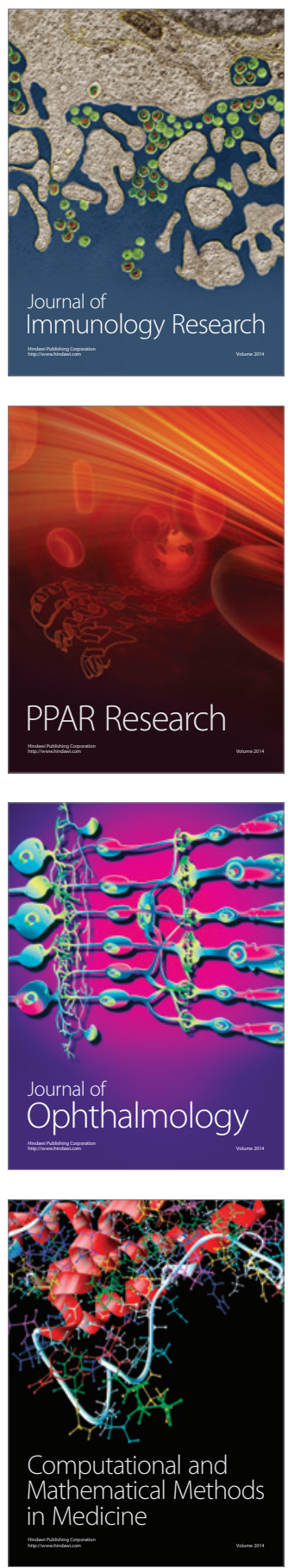

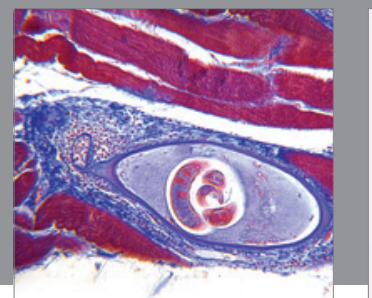

Gastroenterology

Research and Practice
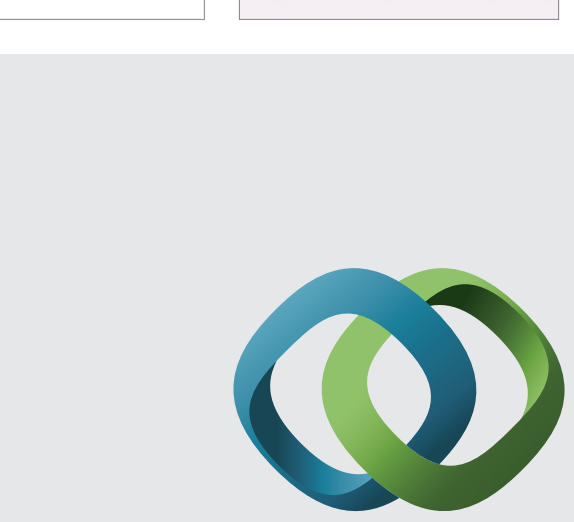

\section{Hindawi}

Submit your manuscripts at

http://www.hindawi.com
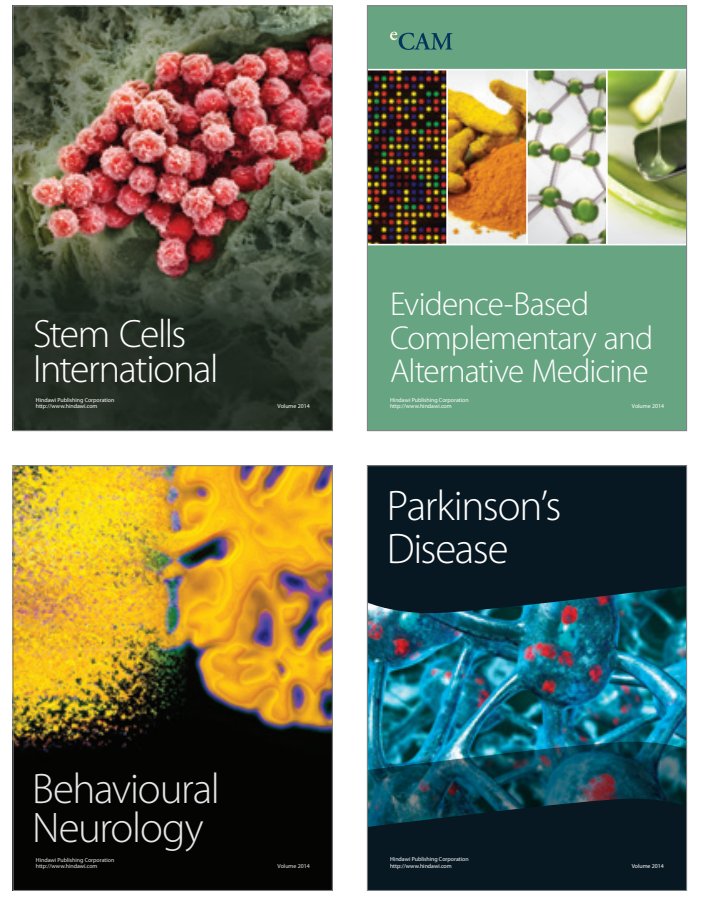
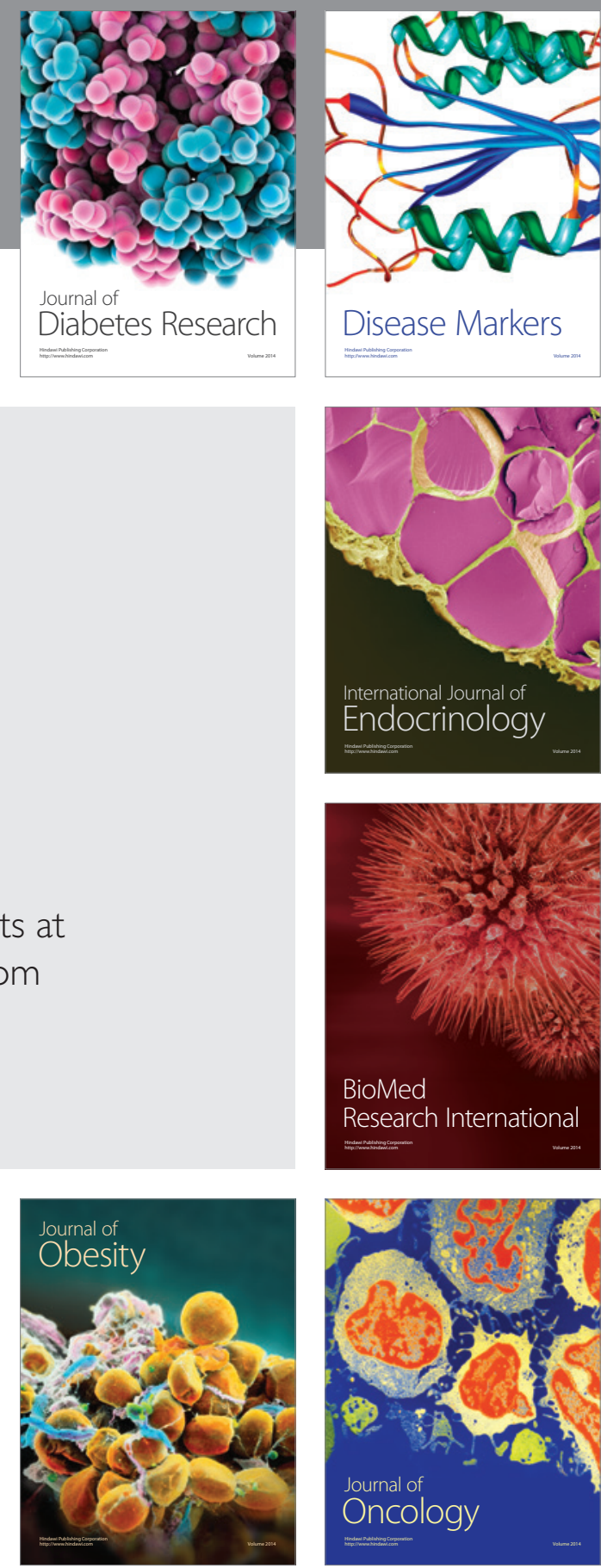

Disease Markers
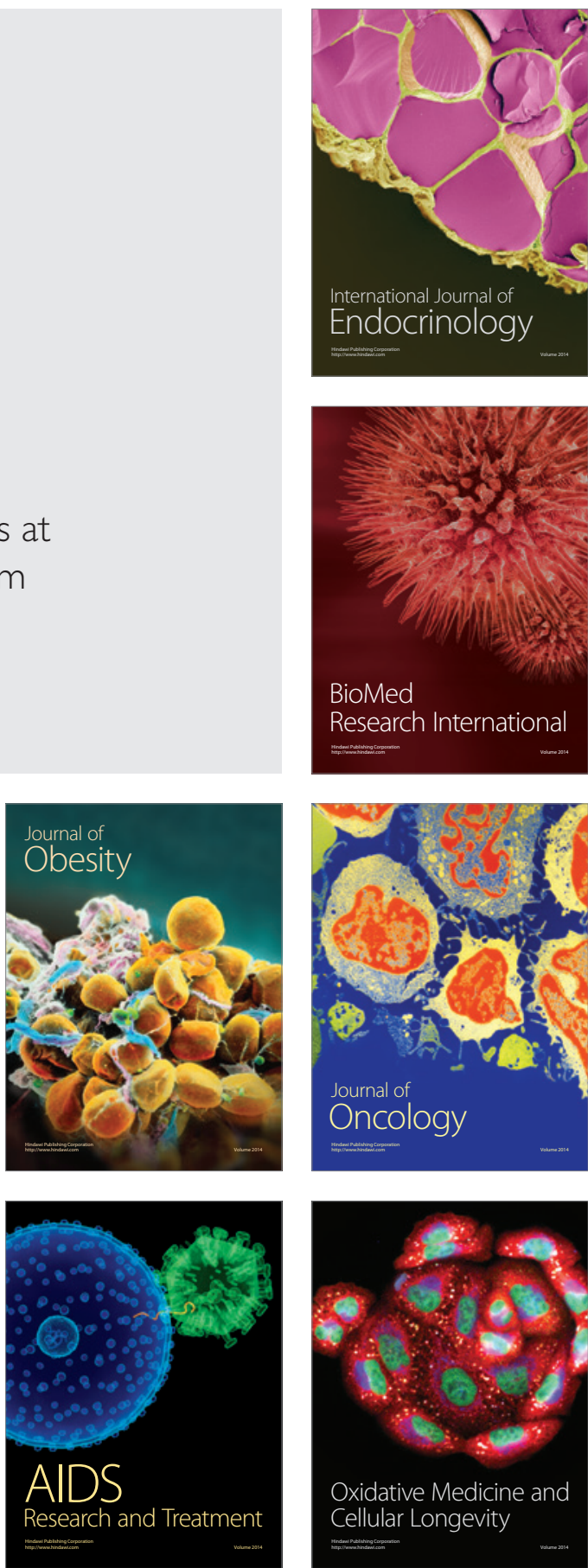